\title{
EXPERIMENTAL STUDY AND COMPUTATIONAL MODELLING OF GAS FIRED PULSE COMBUSTION
}

\author{
I. Smajevic ${ }^{1,2}$ \\ ${ }^{1}$ Mechanical Engineering Faculty of University Sarajevo \\ Vilsonovo setaliste 9, 71000 Sarajevo, Bosnia and Herzegovina \\ 2 JP Elektroprivreda BiH d.d.-Sarajevo (Power Utility) \\ Vilsonovo setaliste 15, 71000 Sarajevo, Bosnia and Herzegovina \\ E-mail: i.smajevic@elektroprivreda.ba
}

\begin{abstract}
The paper presents some results of computational modelling of a gas-fired pulse combustor with aerodynamic valves. The development of the model followed experimental investigations during which the combustor geometry and operating conditions were defined. A simple 'tank and tube' approach was adopted by decomposing the combustor into several elements which were modelled separately, together with the interconnecting processes. The solution was obtained by marching integration in time over several cycles. The model reproduced reasonably well the recorded time history and averaged values of all basic parameters and is expected to complement the experiments aiming to develop a pulse combustor as a device for to cleaning the outer sides of power plants' boiler heating surfaces during operation.
\end{abstract}

Keywords: Pulse combustion, gas-fired, aerodynamic valve, modelling.

\section{INTRODUCTION}

Pulse combustors offer a number of advantages as compared with conventional steadyflow burners (Zinn at al., 1982). Putnam et al. (1986) demonstrated such major features as their efficient combustion and enhanced heat transfer at contact surfaces as a consequence of their higher turbulence level and mixing. Periodic interchange of rapid combustion and quenching lowers the average combustion temperature. The reverse flow of combustion products from the exhaust pipe into the combustion chamber during the low-pressure period in the cycle enable the burning of unburned fuel residual. Both of these effects contribute to the reduction of NOx emission and to favourable conditions for the reduction of SOx from the exhaust gases. The self-pumping mechanism employed here eliminates the need for an external energy supply to pump in air for combustion, as well as the need for a chimney to generate draft for exhaust of combustion products. Pressure pulsations together with the consequent vibrations of the bounding solid surfaces reduce ash deposition and fouling.

Extensive research and development activities in the past have resulted (Putnam et al., 1986) in a variety of proposed designs of pulse combustors, both with mechanical and aerodynamical valves, but only a few types with mechanical valves reached the stage of commercial application. Their main deficiency is a very high noise level, which deters a wider use of pulse combustors in residential space heating and similar applications. Of course this shortcoming may be converted into an advantage when the strong acoustic waves are used for reducing the fouling of exposed surfaces, loosening 
and removing a deposit, or to enhance heat and material transport (drying and conveying of loose material). A reduced control of the process, as well as a lack of flexibility in operation, particularly in the case of aerovalved combustors have also been listed in literature as shortcomings, though some designs have achieved wide ranges of loading in which the combustors could operate in a stable self-pumping regime (Smajević and Hanjalić, 1990).

The lack of understanding of some of the important phenomena on which the operation of the combustor strongly depends has led in the past to predominantly experimental investigations in which the influence of various designs and operating parameters was explored by a trial-and-error method. Mathematical modelling and computer simulation, combined with specific task-tailored experiments, offer new prospects for a revival of research in this highly potential technique and its use in a variety of industrial applications. The present paper describes a simple 'tank and tube' type model, which was developed complementary to the experimental investigation of the performance of a simple aerovalved pulse combustor and the influence upon it of various design parameters. It was envisaged that - once calibrated-the model could serve the purpose of preliminary computer optimization of the combustor and a study of the feasibility of their application to various industrial purposes.

\section{COMBUSTOR DESIGN AND FUNDAMENTAL MEASURING DATA}

This research has aimed at designing a simple and robust pulse combustor which could be used in large size coal fired boilers as a pilot and ignition burner, but also to serve as a turbulizer and generator of an acoustic environment in the boiler by which to promote the reduction of fouling of the gas-side heating surfaces. Applications for other purposes and its use as an autonomous burner has not been excluded, but these possibilities were not primarily the focus of our investigations. Considered was a simple Helmholtz-type combustor with multiple air entry oriented rearward, as suggested in Ponizy and Wojcicki (1985). The present design differs only slightly in concept, but more in scale and in design details which were chosen on the basis of an extensive testing and optimization of the geometry and operating conditions, using propane gas as fuel (Smajević and Hanjalić, 1990; Smajević, 1991). A schematic of the laboratory pulse combustor testing line and a view of the combustor are shown in Figures 1 and 2 respectively.

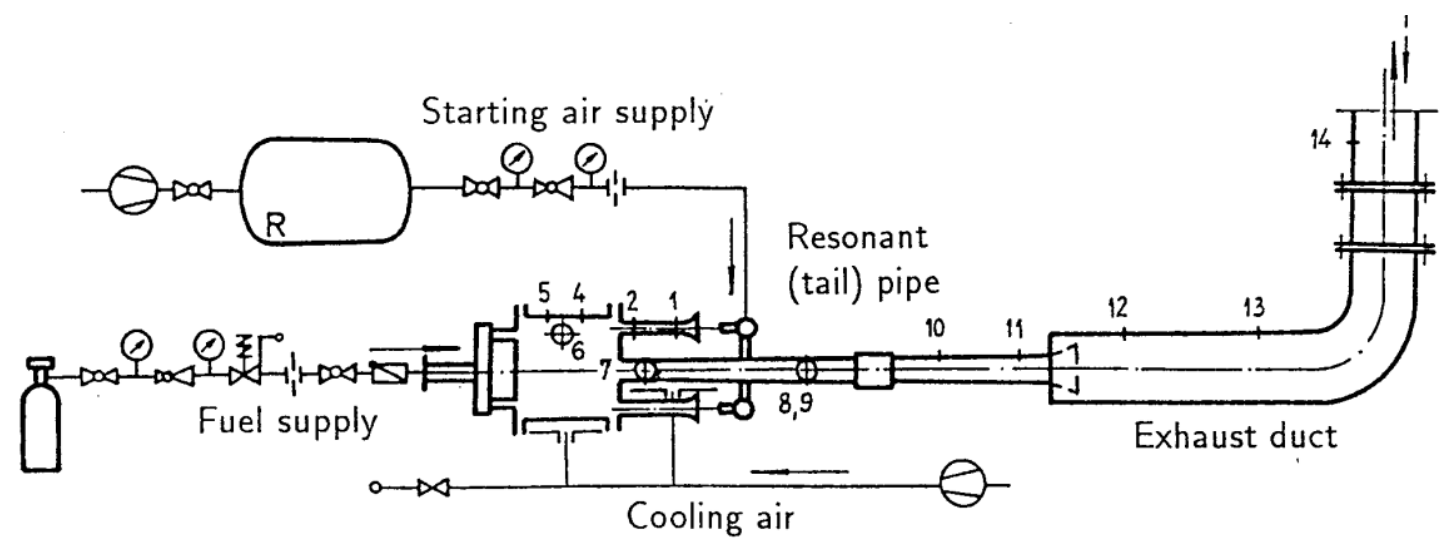

Figure 1: Schematic of the laboratory pulse combustor testing line, MEF of University Sarajevo, 1-14: measuring points 
The combustor, with no moving parts, consists of a cylindrical combustion chamber with four bell-mouthed air suction inlets and a resonant tailpipe mounted to the chamber on the same front wall as the air inlets. The air suction tubes served also as aerodynamic valves. Their cross-section area was reduced toward the end with sharp edges of the tubes protruding into the chamber so as to make a large resistance to the reverse flow. Fuel was introduced continuously through the back chamber wall. The combustor was equipped with fuel- and starting air supply systems. Measurements were carried out at 14 stations indicated in Figure 1. Pulsating pressure was recorded by piezoelectric high sensitivity transducers. The averaged- and instant temperatures were measured by $\mathrm{NiCr}-\mathrm{Ni} 0.1 \mathrm{~mm}$ and $\mathrm{Cr}-\mathrm{Al} 0.0125 \mathrm{~mm}$ thermocouples, respectively, and the composition of the combustion gases - the concentrations of $\mathrm{O}_{2}, \mathrm{CO}_{2}$ and $\mathrm{CO}$ were measured by sampling and analysing the gas mixtures by electronic gas-analysers.

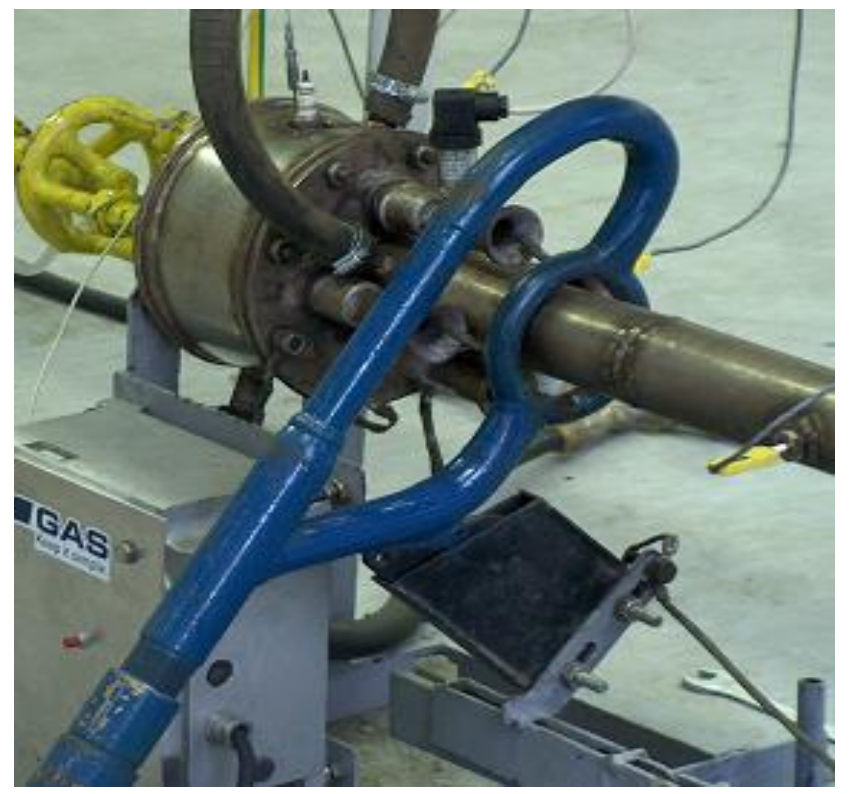

Figure 2: A view of the pulse combustor investigated at the MEF of University of Sarajevo

Typical recordings of pressure pulsations in the combustion chamber (measuring point 4 -lower signal) and in the tail pipe (point 11-upper signal) are shown in Figure 3. The cycle period is about $9.8 \mathrm{~ms}$, corresponding to a frequency of $102 \mathrm{~Hz}$. As can be seen, the pressure pulsations in the combustion chamber follow a close-to-sinusoidal periodic pattern. However, the pattern is visibly asymmetric with respect to the reference atmospheric pressure line, with higher positive amplitudes than negative ones. The high pressure part of the cycle is also more peaked while the low pressure part is flattened. The pressure recording shows also that the curve has a steeper gradient during the compression and a milder one during the expansion. The steeper pressure increase is a consequence of a rapid and intensive combustion. The flattening of the low pressure part of the curve is caused by the resistance to the air inflow through the aerodynamic valves and will be more pronounced if this resistance is higher.

Asymmetry of the pressure amplitudes is illustrated in Figure 4, which shows the positive-, negative- and peak-to-peak (total) pressure amplitudes in the chamber as a function of the combustor power expressed in terms of fuel consumption. As can be 
seen, the difference between the positive and negative amplitudes increases with the increase of the power. The frequency of the pulsations shows only a marginal increase with power, reflecting in fact an increase in the temperature and a corresponding decrease of the fluid density, which in turn reduces the fluid momentum.

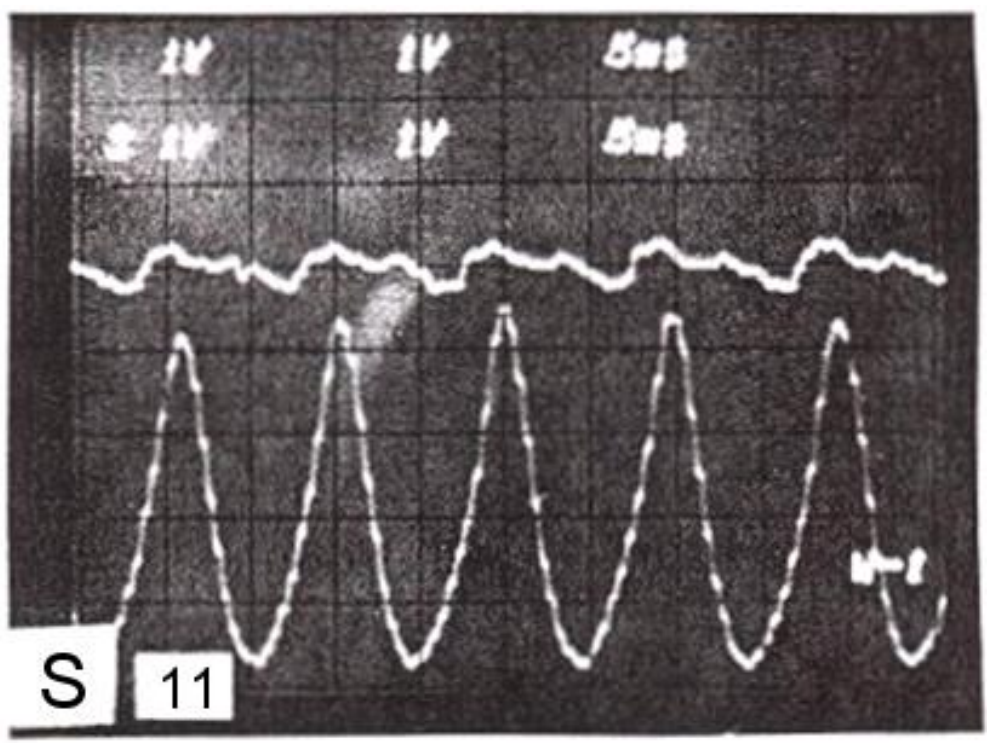

Figure 3: Recordings of pressure pulsations in the combustion chamber-measuring point 4, Figure 1 (lower signal) and in the tail pipe-measuring point 11, Figure 1

(upper signal)

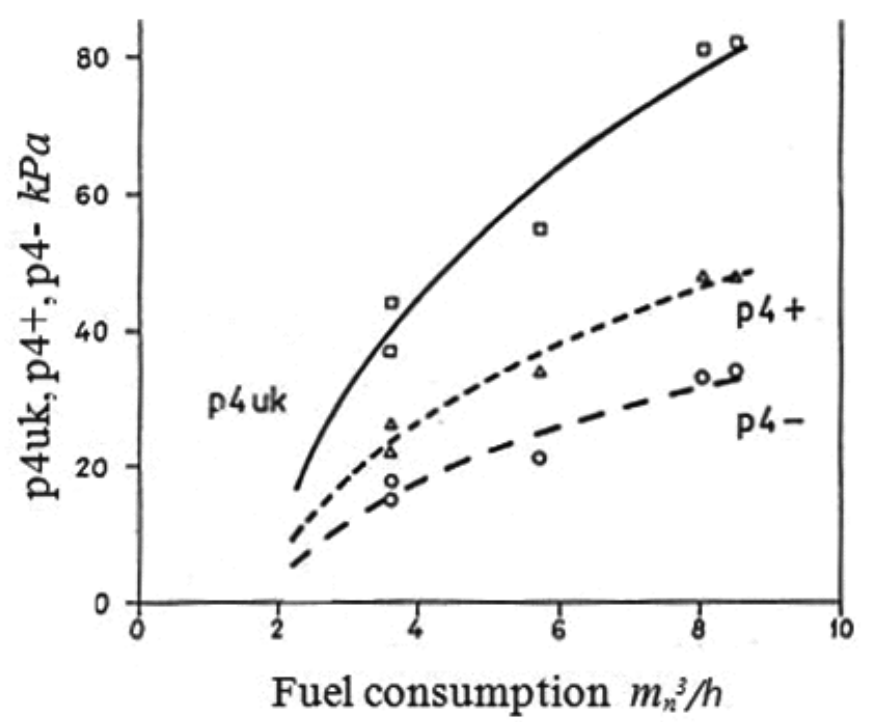

Figure 4: Positive (p4+), negative (p4-) and peak-to-peak (total, p4uk) pressure amplitudes in the chamber as functions of the combustor power expressed in terms of fuel consumption

The presented variables in Figures 3 and 4 are only some of many which were measured and which served as an experimental basis for the validation of the mathematical models. Of course, small perturbations, visible on both pressure records in 
Figure 3 originate from the pressure reflections and wave interactions and they could not be reproduced by the considered model.

\section{MATHEMATICAL MODEL}

An idealized cycle of an aerovalved pulse combustor may be decomposed into four phases: combustion (which starts with re-ignition), expansion, purge and recharge, and recharge and compression. The beginning of each phase is indicated by the numbers 1 , 2,3 and 4 on the cycle in the p-v diagram in Figure 5 together with a schematic representation of their occurrence in the considered type of the combustor.

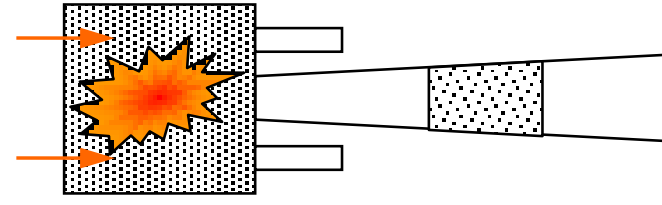

1-2: Re-ignition and combustion

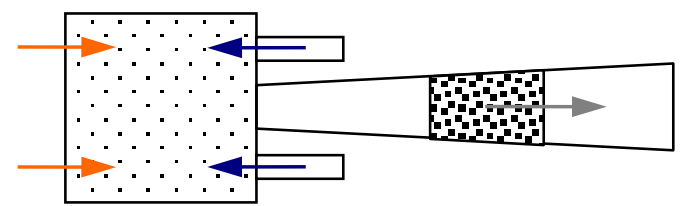

3-4: Purge and recharge

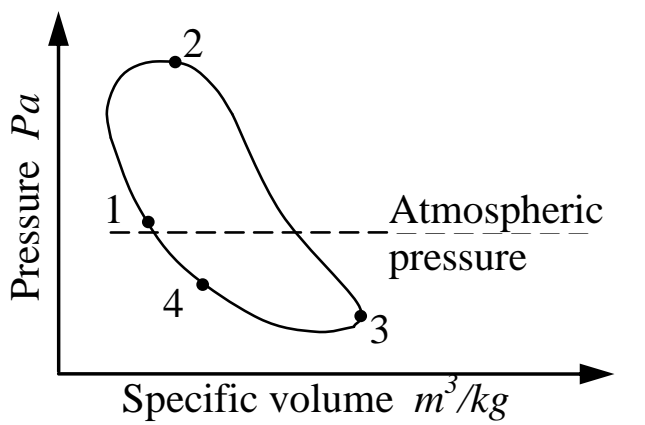

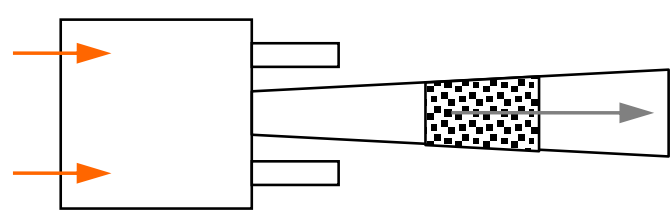

2-3: Expansion

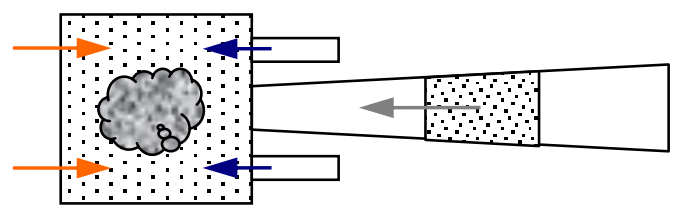

4-1: Recharge and compression

Caption:

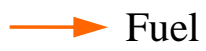

$\longrightarrow$ Air

$\longrightarrow$ Flue gas

Figure 5: An idealized cycle of the considered aerovalved Helmholtz-type pulse combustor

A possible approach to modelling the whole process is to model separately each phase in the cycle. Such a model would require a number of assumptions and empirical inputs which would influence the final solution and seriously limit the applicability of the model to predictions of the performance of a new combustor with design parameters outside the range of validity of the those assumptions and empirical correlations. Here instead has been chosen a 'tank and tube' approach by which the processes in various segments of the combustor were modelled separately and these models then coupled by relations which describe the mutual interactions - outflow and inflow of the variables from one segment of the combustor to another. For that purpose, the combustor was decomposed into several sections: the bell-mouthed air suction tubes which also act as aerodynamic one-way valves, the combustion chamber and the resonant tail pipe. Each segment has been modelled separately as an entirety represented by its own control 
volume to which basic conservation laws were applied. Processes in some elements were further decomposed if different relationships were to be applied. Interconnecting relationships which represent the mutual interactions were established by approximation of the flow processes between each combustor element.

\section{Combustion Chamber}

The equation of conservation of energy for the control volume $\left(V_{c}\right)$ identified with the combustion chamber; the application of the ideal gas equation of state yields the following expression for the rate of change of pressure in the chamber:

$$
\left(\frac{d p_{c}}{d t}\right)_{V_{c}}=-\frac{k_{g}-1}{V_{c}}\left[4 \dot{m}_{1}\left(c_{p g} T_{*}+\frac{u_{*}^{2}}{2}\right)+\dot{m}_{3}\left(c_{p g} T_{3}+\frac{u_{3}^{2}}{2}\right)-\dot{Q}_{c o}+\dot{Q}_{l c}\right]
$$

Where $\dot{m}$ denotes the mass flow rate, while $u$ and $T$ stand for the fluid velocity and temperature, respectively. Index * corresponds to the throat of the air inlet tube within the combustion chamber, while index 3 denotes the throat of the tail pipe, and index 1 the measuring point 1 , Figure 1. Of course, $\dot{m}_{1}$ and $\dot{m}_{3}$ take appropriate signs depending on the flow direction.

The supplied heat $\dot{Q}_{\text {co }}$ to the combustion of the fuel-air mixture is defined by the equation of Vibe (Smajević, 1991), as follows:

$$
\dot{Q}_{c o}=6.9(n+1) H_{d} \frac{m_{f c}}{t_{c o}}\left(\frac{t}{t_{c o}}\right)^{n} \exp \left[-6.9\left(\frac{t}{t_{c o}}\right)^{n+1}\right]
$$

where $m_{f c}$ denotes the total mass supplied over a cycle and $t_{c o}$ the time duration of combustion in each cycle. $\dot{Q}_{l c}$ represents the heat loss of the combustion gases over a cycle due to the cooling of the combustion chamber, which has to be estimated or supplied from experiments.

Mass conservation for the chamber yields

$$
\left(\frac{d m_{c}}{d t}\right)_{V_{c}}=4 \dot{m}_{1}-\dot{m}_{3}
$$

\section{Air Intake Tubes}

The velocity $\mathrm{u}_{*}$ is obtained from the energy equation written for the air intake tube, which takes different forms depending on the flow direction. During the expansion (phase 2-3, Figure 5), a reverse flow of the combusted gases will occur through the air intake tubes, but due to the action of the aerodynamic valves this mass flow rate is expected to be small. Therefore, a fairly crude approximation of this process will suffice. It has been presumed that the gas exit velocity through the bell-mouth will be equal to the velocity prevailing at the point ' 1 ' and this velocity is first computed from the energy equation written for a cross-section in the chamber $\left(\mathrm{u}_{\mathrm{c}} \approx 0\right)$ and for the outside atmospheric condition, yielding the expression 


$$
u_{1}^{\prime}=\sqrt{\frac{2\left(p_{c}-p_{o}\right)}{\rho_{m}\left(1+\xi_{1}+\lambda_{1} \frac{l}{d}\right)}}
$$

where the prime indicates an assumed value which will be determined by iteration, $\xi_{1}$ represents the pressure loss coefficient of the aerodynamic valve for the reverse flow, and $\lambda_{1}$ is the friction factor for the suction tube. The local density was taken as the arithmetic mean between the fluid density at the point 1 (unknown in advance and obtained by iteration) and in the chamber. The temperature $T_{*}$ was evaluated from the expression for the total temperature assumed to correspond to that prevailing in the combustion chamber. The continuity equation, written for the cross-sections $*$ and 1 , enabled the computation of the velocity $u_{*}$ '. Other variables have standard meanings.

In the case of the air inflow to the chamber, (phases 3-4 and 4-1, Figure 5) the air inflow process was decomposed into three phases. For the intake through the bellmouth we have assumed that isentropic conditions prevail so that the air inflow velocity at the point ' 1 ' can be evaluated from the equation

$$
u_{1}=-\sqrt{\frac{2 \kappa_{a}}{\kappa_{a}-1} \frac{p_{o}}{\rho_{o}}\left[1-\left(\frac{p_{1}}{p_{o}}\right)^{\frac{\kappa_{a}-1}{\kappa_{a}}}\right]} .
$$

From the expression for the pressure drop between points 1 and 2, the isothermal relation was used which gives the value of the pressure at point 2:

$$
p_{2}=-\lambda_{2} \frac{l}{d} \frac{\rho u_{1}^{2}}{2}+\sqrt{\left(\lambda_{2} \frac{l}{d} \frac{\rho u_{1}^{2}}{2}\right)^{2}+p_{1}^{2}}
$$

The air inflow through the aerodynamic valve has been assumed to be isentropic so that its exit velocity at the valve throat can be written as

$$
u_{*}=-\sqrt{u_{2}^{2}+\frac{2 \kappa_{a}}{\kappa_{a}-1} \frac{p_{2}}{\rho_{2}}\left[1-\left(\frac{p_{c}}{p_{2}}\right)^{\frac{\kappa_{a}-1}{\kappa_{a}}}\right]}
$$

\section{Resonant Pipe}

Because of its specific role, in particular, during the chamber's charging with fresh airfuel mixture, the tail pipe could not be considered as a simple orifice, since the pipe dimensions and shape play an important role. Likewise, since the velocity in the pipe could not be neglected, it could not be treated as a reservoir. Hence in the process of modelling the tail pipe there was considered a separate control volume to which the conservation laws were applied. The momentum equation yields directly the rate of change of the mean velocity in the pipe: 


$$
\left(\frac{d \bar{u}}{d t}\right)_{V_{r}}=\frac{1}{m_{r}}\left[\dot{m}_{3} u_{3}-\dot{m}_{e} u_{e}+p_{3} A_{3}-p_{o} A_{e}+p_{r}\left(A_{e}-A_{3}\right)-f \frac{\bar{\rho}\left|\bar{u}_{3}\right|^{3}}{2 \bar{u}} A_{f}-\bar{u} \frac{d m_{r}}{d t}\right],
$$

where $A_{3}$ and $A_{e}$ denote the cross-sectional areas at position 3 (throat of the tailpipe) and at the pipe exit $e$, respectively, $A_{f}$ is the internal surface area of the pipe, $m_{r}$ is the instant fluid mass in the pipe, while $f$ is the skin friction factor on the pipe interior walls.

The equation of energy yields the rate of change of pressure at the throat of the tailpipe:

$$
\left(\frac{d p_{3}}{d t}\right)_{V_{r}}=\frac{2\left(\kappa_{g}-1\right)}{V_{r}}\left[m_{3}\left(c_{p g} T_{3}+\frac{u_{3}^{2}}{2}\right)-\dot{m}_{e}\left(c_{p g} T_{e}+\frac{u_{e}^{2}}{2}\right)-f \frac{\bar{\rho} \bar{u}^{3}}{2} A_{f}-\dot{Q}_{l r}\right] .
$$

The equation contains the heat loss in unit time to the surroundings through the walls of the resonant pipe:

$$
\dot{Q}_{l r}=m_{3} c_{p g}\left(T_{3}-T_{e}\right)
$$

which has to be evaluated on the basis of a specified heat transfer coefficient through the tailpipe walls, or by using the obtained value of the exit temperature $T_{e}$.

Eqs 1 to 10 with some auxiliary relationships constitute basically the mathematical model of the process. It consists of a set of ordinary differential equations complemented with several algebraic expressions. The differential equations were solved by the 4th order Runge-Kutta method with Gill's modification and adjustable time interval. The integration starts with an assumed distribution of basic parameters at the key positions in the combustor and the solution was carried out by marching in time over a number of cycles until the results become sufficiently repeatable. It was found that a desirable reproducibility was achieved usually after three or four cycles. The model requires several empirical inputs. These include the friction factors in the inletand tail pipe, the pressure drop coefficient for the back flow through the aerodynamic valve, and heat transfer coefficient for the combustor walls (in particular for the tail pipe). These data were supplied from the appropriate literature.

A major problem is associated, however, with the specification of the ignition (re-ignition) point 1 in the cycle, Figure 5. In fact, in the case of an aerovalved pulse combustor, the positions of all points in the cycle, except for point 2, can not be located in advance, but points 3 and 4 can be obtained from the model computation. However that is not the case with point 1 , which indicates the re-ignition of the combustible mixture. Re-ignition depends on a number of factors, e.g., the amount and temperature of the combusted gases which flow back into the chamber, the temperature distribution inside the chamber and at its walls, and others, which all depend very much on the design features of each combustor. This position influences the final solution considerably and its determination has been the subject of research of several authors (Putnam at al.,1986). A reliable modelling of the cycle without prior specification of these characteristic positions would require the application of a field modelling technique which would result in a detailed distribution of all the field variablesvelocity, temperature and concentrations--at least in the combustion chamber. Since 
here what has been opted for is a simple plug flow modelling, information about the conditions (i.e., the position in the $p-v$ diagram) of the ignition point has to be supplied or the solution searched for by trial and error and the model verified on the basis of experiments.

\section{RESULTS AND DISCUSSION}

As was pointed out, the position of the re-ignition point has a major influence upon the prediction of the combustor performance and the conditions for the location of this point in term of thermodynamic properties have to be specified. Several different conditions for re-ignition were explored by comparing the modelling results with experiments, e.g. the re-ignition was located at the instant when the pressure in the combustion chamber starts to rise above the atmospheric level, or in the second attempt the re-ignition was identified with the instant of change of flow direction of combustion products in the tail pipe (onset of the reverse flow), etc. However, the best results were obtained when the re-ignition was identified with the moment at which the temperature of the fresh air-fuel mixture starts to rise, as shown in Figure 6. In its time coordinate, this position is somewhere between the previous two.

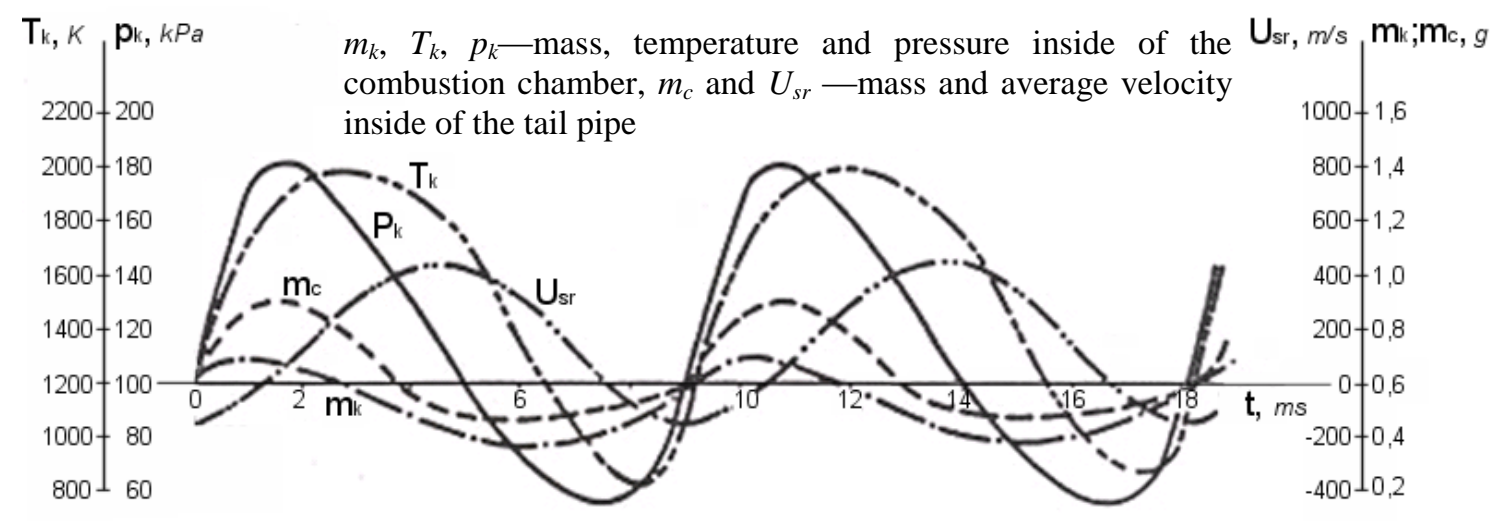

Figure 6: Variation of masses, temperature and pressure inside the combustion chamber, plotted against time.

As can be seen from the figure, the temperature of the mixture in the combustion chamber starts to rise even before the ignition occurs while the pressure in the chamber is still below the atmospheric level. This rise is a consequence of the reverse flow of the combustion products, which mix with the cooler air-fuel mixture. The returned combustion products increase the overall mass of the gases in the chamber, which absorb the heat released by combustion so that an excessive rise of temperature is absent. The obtained results agree well with the experimental data both in averaged values and-though less satisfactory-in details. The figure shows a satisfactory degree of similarity in the shapes of the two pressure curves, though some discrepancies are noticeable. So, for example, the computed positive peak values of the pressure are higher, and the computed gradient of the pressure rise corresponding to the combustion phase is higher than measured, which could be caused by an inadequacy in some of the empirical inputs (e.g., the Vibe equation, heat loss through the walls), but also by a still insufficient precision of the location of the re-ignition point. Averaged properties seem to be in much better agreement. For instance, the computed frequency of $103 \mathrm{~Hz}$ 
corresponds closely to the measured $102 \mathrm{~Hz}$, the temperature variation between 500 and $1700 \mathrm{C}$ yields an average value of about $1100 \mathrm{C}$, which is very close to the measured one. As can be seen, the peak temperatures appear in very short intervals which last between 2 to $5 \mathrm{~ms}$. The probability for generation of NOx in such conditions is very much reduced as compared with continuous combustion, which illustrates one of the mentioned advantages of pulse combustors.

The model supplies a number of other relevant parameters not shown here, like the air inflow rate, fuel consumption, total heat release, combustion power and others. After the model is fully verified, these parameters can be used for optimization of design and operating conditions, but also to supply the correlations which could serve as guidance for the operation of the combustor in practice.

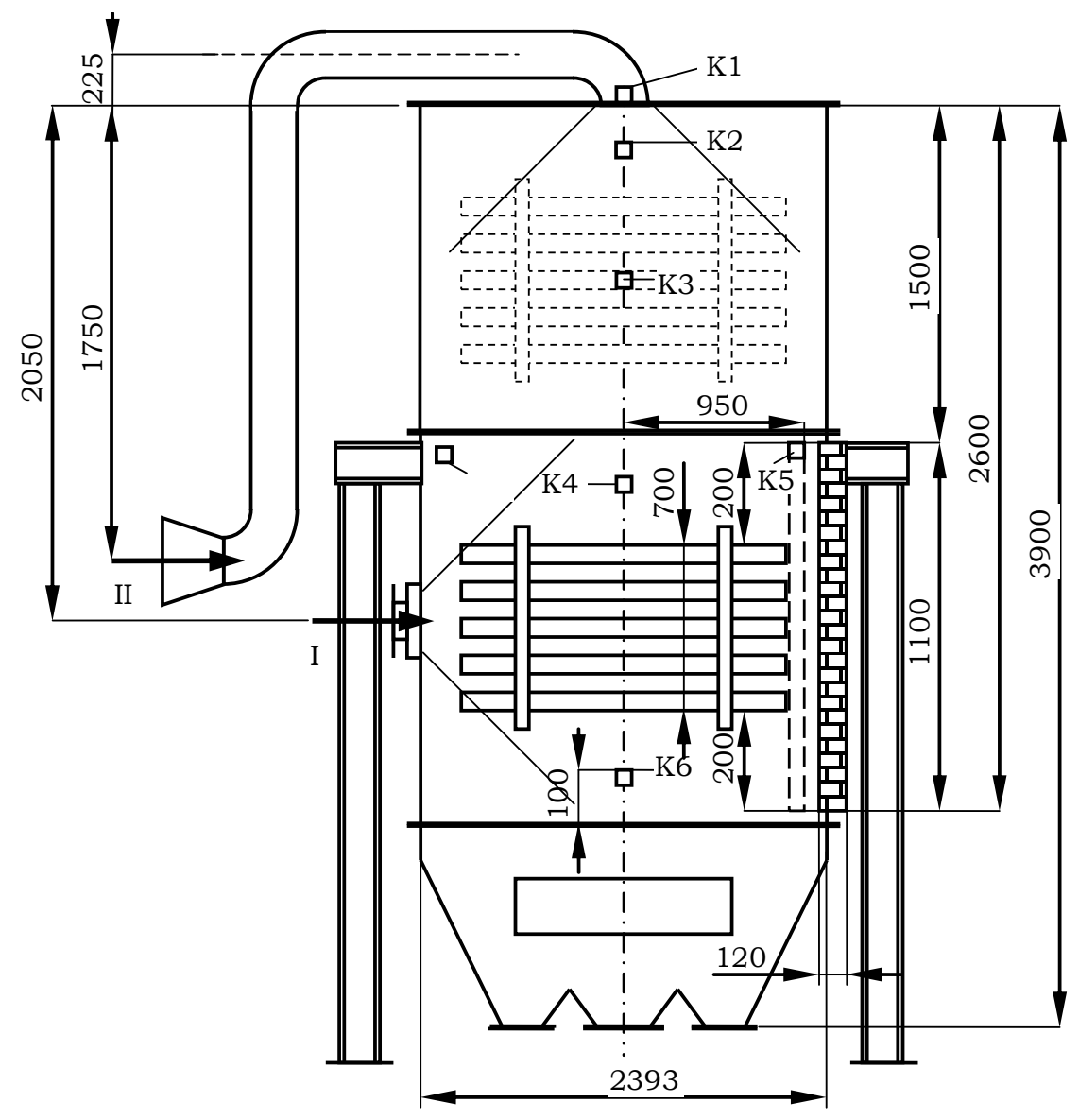

Figure 7: Basic dimensions of the boiler model; I, II-burner connections, $\mathrm{K} 1-\mathrm{K} 6$ - measurement points

On the basis of highly satisfactory results achieved in twenty-five years of experience in using of our own model of the detonation wave technique applied for online cleaning of the outer sides of boiler heating surfaces in TPP Kakanj, Bosnia and Herzegovina (Smajević and Hanjalić, 2004), the research team of the Mechanical Engineering Faculty of the University of Sarajevo has decided to investigate the possibility of applying the already described model of pulse combustors also as a boiler heating surfaces cleaning device.

Inside the boiler model, Figure 7, installed in the Combustion Laboratory of the MEF of the University of Sarajevo, a bundle of tubes is mounted representing the 
convective parts of the boiler. In the case when the tube bundle is in the upper position, the bottom of the boiler model represents the boiler furnace. Application of the pulse combustion burner on the boiler model refers basically to two zones: the boiler-furnace/ burner connection I-Figure 8, and to the convective part of the boiler/ burner connection II-Figure 7. Some results of the laboratory experiments already carried out are to be found for instance in Hodžić et al. (2009).

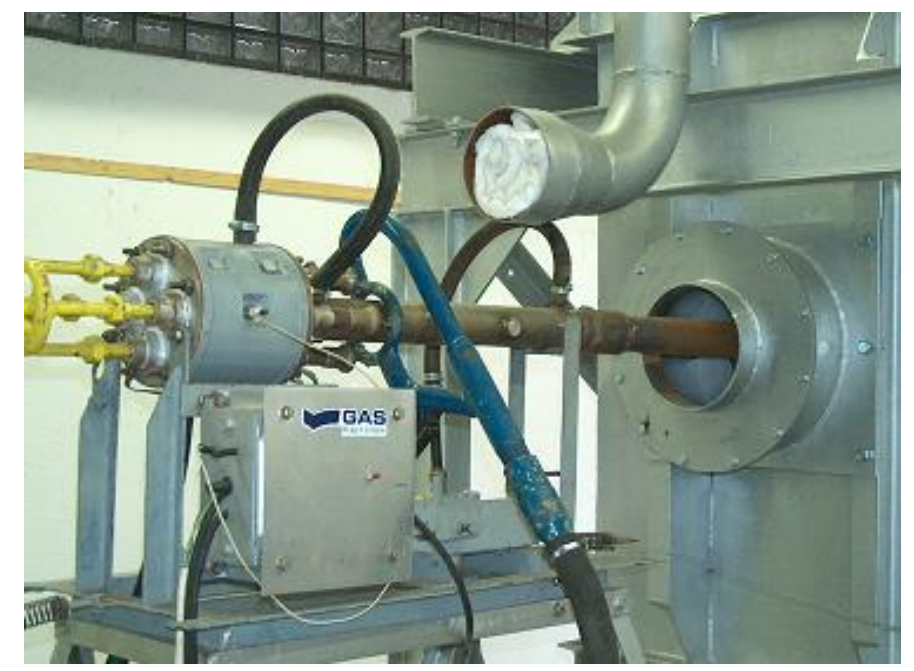

Figure 8: A view of the burner placed on the boiler model at connection I

\section{CONCLUSIONS}

In spite of its simplicity, the mathematical model of the considered aerovalved pulse combustor reproduced reasonably well the measured thermodynamic cycle, the corresponding time history of all oscillating variables and their averaged values which determine the combustor operation. Because of its simplicity, the model requires a supply of several empirical parameters which can not be computed at the present level of modelling. However, apart from the definition of conditions for the re-ignition, most of the empirical inputs can be supplied on the basis of data or correlations available in the literature. The present results are still preliminary and require further refinement and testing. However it is believed that the adopted model could be expected to replace - at least in part - tedious experimental investigations and to serve the purpose of further optimization of the design and operating parameters in a broader range than was possible to cover in a laboratory. The model can also supply some further insight into the influence of various design and operating parameters on the physical process. Experimental investigations aimed at discovering whether such a type of pulse combustor could serve as an on-line cleaning device for the outer sides of heating surfaces in large power boilers based on coal combustion are already going on, and will be continued.

\section{ACKNOWLEDGEMENTS}

The author sincerely thanks Prof. Dr. K. Hanjalic (Prof. Emeritus, Delft University of Technology, Netherlands) and M.Sc. N. Hodzic (Mechanical Engineering aculty, University of Sarajevo) for useful cooperation. 


\section{REFERENCES}

Hodžić, N., Metović, S. and Smajević, I. (2009) Pulse combustion burner as cleaning device of boiler heating surfaces. 13th International Research/Expert Conference Trends in the Development of Machinery and Associated Technology-TMT 2009, pp. 1204-1208

Ponizy, B. and Wojcicki, S. (1985) On modelling of pulse combustors. $20^{\text {th }}$ Symposium (International) on Combustion, 20 (1), 2019-2024.

Putnam, A.A., Belles, F.E. and Kentfield, J.A.C. (1986) Pulse Combustion. Progress in Energy and Combustion Science, 12 (1), 43-79.

Smajević, I. (1991) Investigation of pulsating combustion with analysis of possible applications. Ph.D. Thesis. University of Sarajevo, Bosnia and Herzegovina.

Smajević, I. and Hanjalić, K. (1990) Pulsating combustion of liquid petroleum gas. Proc. of $8^{\text {th }}$ Yugoslav Symp. on Thermal Engineering -JUTERM-90, pp. 503-511

Smajević, I. and Hanjalić, K. (2004) Zwanzig Jahre erfolgreiche Anwendung der Stosswelen-Reinigungstechnik in einem mit Kohle befeurtem Kraftwerk. International Journal for Electricity and Heat Generation-VGB PowerTech 8/2004, pp. 71-75.

Zinn, B.T., Miller, N., Carvalho, J.A. and Daniel, B.R. (1982) Pulsating combustion of coal in a Rijke type combustor. Nineteenth Symposium (International) on Combustion, 19 (1), 1197-1203.

\section{NOMENCLATURE}

$c_{p}$ - specific heat for a constant pressure

$d$-diameter

$f$-coefficient of friction

$l$ - length

$m$-mass

$\dot{m}$-mass flow rate

$m_{f_{c}}$ - total quantity of fuel supplied in combustion chamber during one cycle

$p$-pressure

$t$ - time

$u$-velocity

$v$ - specific volume

$A$-surface area

$H_{d}$-lower heat value of fuel

$\dot{Q}$-heat (released or transported) in unit of time

$T$-temperature

$V$-volume

$\xi$-local pressure drop coefficient

$\lambda$ - coefficient of friction

$\rho$-specific mass

$\kappa$ - exponent of adiabatic curve
Indices:

$a$-air

$c$ - combustion chamber

co-combustion (process)

$e$ - outlet of the resonant tube

$f$-inner surface of resonant tube

$g$-flue gas

$l$-loss (of heat)

$r$-resonant tube

$o$-atmosphere

1;2 — start (at bell-shaped inlet) and end (at aerodynamical valve) of straight tube of air inducer

3 - throat of the resonant tube

* - throat of the aerodinamical valve

Superscripts:

- assumed value (iterative calculation)

- _ average value 